\title{
Gas Pocket Generation in MAG Welding of Galvanized Steel Sheet
}

\author{
Yutaka NISHIKAWA, Tetsuo SUGA and Toshihiko NAKANO
}

Kobe Steel, Ltd., Urakouchi, Miyamae, Fujisawa, Kanagawa-ken, 251 Japan.

(Received on April 19, 1995; accepted in final form on June 19, 1995)

\begin{abstract}
The effects of welding parameters, wire compositions and others on the gas pocket (pit, blowhole) generation have been studied regarding MAG welding of galvanized steel sheets, and the mechanism of the gas pocket generation also has been investigated.

As to the welding joint type and position, lap joint and vertical-down position make the number of generations large in comparison with others. The increase in welding current and speed or Ar content of shielding gas also furthers the gas pocket generation. In contrast, the application of metal-cored wire in $\mathrm{CO}_{2}$ welding or pulsed current welding machine in MAG welding with $\mathrm{Ar}-\mathrm{CO}_{2}$ mixture gas reduces the generation. The increase in $\mathrm{C}, \mathrm{Ti}$ and $\mathrm{P}$ content of the metal-cored wire is effective for the reduction of gas pocket generation. Through these investigations, special metal-cored wire for $\mathrm{CO}_{2}$ welding of galvanized steel sheets has been developed, and the wire is currently used in car manufacturing, house construction and other fields.

Based on the above phenomena, zinc vapor seems to be the main cause of gas pocket generation. These phenomena can be mainly explained by the penetration depth which corresponds to the amount of zinc vapor, and by the stability of short-circuiting arc which influences the coming up and release of zinc vapor through the molten pool.
\end{abstract}

KEY WORDS: gas pocket; pit; blowhole; galvanized steel sheet; MAG welding; welding condition; welding wire composition; welding power source.

\section{Introduction}

The applications of galvanized steel sheets are positively being considered to use in manufacturing industries related to automobiles, housing, electrical machines, etc. ${ }^{1)}$ MAG welding of galvanized steel sheets, however, is plagued with troubles such as gas pocket (pit, blowhole) and spatter. ${ }^{2,3)}$ The present paper surveys the cause of gas pocket generation and the effects of welding conditions, types of wires and welding machines on the generation of gas pockets in particular and discusses how to suppress the generation of gas pockets.

\section{Experimental Procedure}

\subsection{Welding Materials}

In the present experiments to study the cause of gas pocket generation and the effect of welding conditions on the generation of gas pockets, a solid wire $(1.2 \mathrm{~mm} \phi)$ conforming to JIS Z3312 YGW12 was taken as the welding material. For the purpose of investigating the effect of differences in welding materials, the products available from the market listed in Table 1 were employed. From among these products, the metal-cored wire with a relatively high resistance to gas pocket generation were selected to study the effect of wire composition on the gas pocket generation. Table $\mathbf{2}$ gives the compositions of these wires.
As a base metal, a galvannealed steel sheet of $2.3 \mathrm{~mm}$ thickness with both sides plated shown in Table 3 was mainly employed. Zinc coated amount was generally $90 / 90 \mathrm{~g} / \mathrm{m}^{2}$.

\subsection{Welding Methods and Welding Conditions}

As illustrated in Fig. 1, the welding was generally done at flat position with lap joint. In the experiment the sheets were cramped with the root gap set at $0 \mathrm{~mm}$, which promoted the gas pocket generation.

As indicated, standard welding conditions were specified as listed in Table 4, with welding current (120, 160, $240 \mathrm{~A})$, welding speed $(30,60,90,120 \mathrm{~cm} / \mathrm{min})$ and shielding gas composition (100\% $\mathrm{CO}_{2}, 50 \% \mathrm{Ar}-50 \% \mathrm{CO}_{2}$, $80 \% \mathrm{Ar}-20 \% \mathrm{CO}_{2}$ ) variously changed. Welding positions (flat, horizontal, vertical-down) and welding power sources (thyristor-controlled, inverter-controlled, in-

Table 1. Manufactured welding consumables for tests.

\begin{tabular}{clllc}
\hline No. & $\begin{array}{c}\text { Manufactured welding } \\
\text { consumables for tests }\end{array}$ & \multicolumn{2}{c}{ Applicable standard } & $\begin{array}{c}\text { Wire dia. } \\
\text { (mm) }\end{array}$ \\
\cline { 3 - 4 } & Solid wire & YGW12 & A5.18 ER70S-G & 1.2 \\
2 & Metal-cored wire & YFW24 & A5.20 E71T-1 & 1.2 \\
3 & Flux-cored wire & YFW24 & A5.20 E71T-1 & 1.2 \\
4 & Self-shielded wire & YFW12 & A5.20 E71T-11 & 2.0 \\
5 & Covered electrode & D4313 & A5.1 E6013 & 3.2 \\
\hline
\end{tabular}


Table 2. Compositions of experimental metal-cored wires.

\begin{tabular}{|c|c|c|c|c|c|c|c|c|}
\hline \multirow{2}{*}{ No. } & \multicolumn{8}{|c|}{ Wire compositions $(\mathrm{wt} \%)^{*}$} \\
\hline & $\mathrm{C}$ & $\mathrm{Si}$ & $\mathrm{Mn}$ & $P$ & $S$ & $\mathrm{Ti}$ & Others & $\mathrm{Fe}$ \\
\hline 1 & $\underline{0.04}$ & 0.8 & 2.1 & 0.012 & 0.008 & 0 & 0.9 & Bal. \\
\hline 2 & $\underline{0.08}$ & $"$ & $" \prime$ & " & $"$ & " & $"$ & $"$ \\
\hline 3 & $\underline{0.13}$ & 0.8 & 2.1 & 0.012 & 0.008 & $\underline{0}$ & " & $"$ \\
\hline 4 & $\overline{0.21}$ & $\overline{" \prime}$ & $\overline{\prime \prime}$ & $\overline{" \prime \prime}$ & $\overline{\prime \prime}$ & $\overline{-}$ & " & $n$ \\
\hline 5 & $\underline{0.25}$ & $"$ & $"$ & " & $"$ & " & " & $"$ \\
\hline 6 & 0.13 & $\underline{0.5}$ & $"$ & $"$ & " & " & " & $"$ \\
\hline 7 & " & $\underline{1.3}$ & " & " & " & " & " & " \\
\hline 8 & " & 1.6 & $"$ & " & " & " & " & " \\
\hline 9 & $"$ & 0.8 & 1.2 & $"$ & $"$ & $"$ & " & $"$ \\
\hline 10 & " & " & $\underline{1.7}$ & " & " & " & $"$ & $"$ \\
\hline 11 & " & " & 2.8 & " & " & " & $"$ & $"$ \\
\hline 12 & $"$ & $"$ & 2.1 & $\underline{0.050}$ & " & " & " & $"$ \\
\hline 13 & $"$ & " & $"$ & 0.108 & $"$ & " & " & $"$ \\
\hline 14 & $"$ & $"$ & $"$ & 0.012 & $\underline{0.04}$ & $"$ & $"$ & $"$ \\
\hline 15 & $"$ & " & $"$ & " & $\underline{0.08}$ & $"$ & " & " \\
\hline 16 & $"$ & " & " & " & 0.008 & $\underline{0.03}$ & " & " \\
\hline 17 & " & " & " & " & " & $\underline{0.10}$ & $"$ & $"$ \\
\hline 18 & " & " & " & " & " & $\underline{0.20}$ & $"$ & $"$ \\
\hline
\end{tabular}

* Flux percentage : $15 \mathrm{wt} \%$

Sectional shape : Abutting shape

Wire sheath : Mild steel

Table 3. Base metal.

(Zn: $\left.90 / 90 \mathrm{~g} / \mathrm{m}^{2}\right)$

Galvannealed steel sheet ( $\mathrm{Zn}: 45 / 45,60 / 60,90 / 90 \mathrm{~g} / \mathrm{m}^{2}$ )

Noncoated steel sheet

$2.3^{\mathrm{l}} \times 75^{\mathrm{w}} \times 500^{1} \mathrm{~mm}$

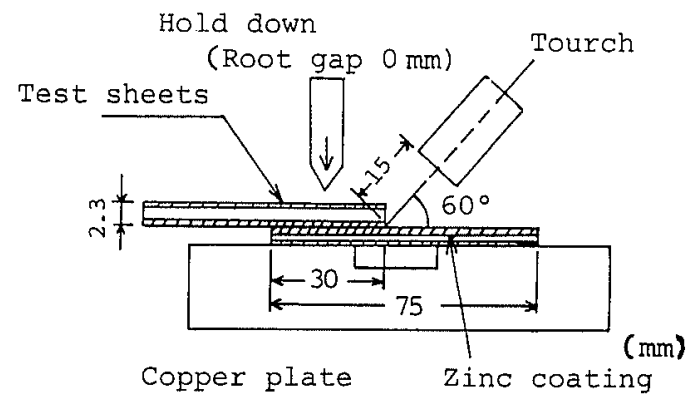

Fig. 1. Welding procedure.

Table 4. Standard welding parameters.

\begin{tabular}{lc}
\multicolumn{1}{c}{ Parameters } & Values \\
\hline Welding current & $120 \mathrm{~A}$ \\
Arc voltage & $18 \mathrm{~V}$ \\
Welding speed & $60 \mathrm{~cm} / \mathrm{min}$ \\
Shielding gas and flow rate & $100 \% \mathrm{CO}_{2}, 20 \mathrm{l} / \mathrm{min}$ \\
Tip-plate distance & $15 \mathrm{~mm}$ \\
Torch angle & $60^{\circ}$ (see Fig. 1$)$ \\
Electrode polarity & Electrode positive
\end{tabular}

verter-controlled pulsed current) were also changed to study their effect on the gas pocket generation.

\subsection{Observation Method of Gas Pocket}

The chemical composition of the gas in blowholes was analyzed by gas chromatography. In this method, a piece including blowholes was cut out from the test sheet, then

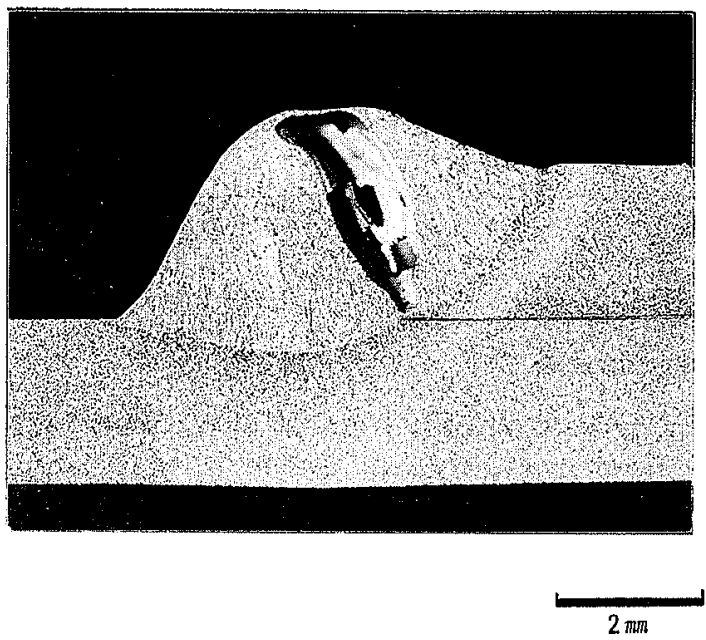

Fig. 2. Example of blowhole.

the piece was twisted off in $\mathrm{He}$ atmosphere within the test chamber and the gas generated thereby was analyzed. ${ }^{4)}$

Meanwhile the chemical composition of the wall of blowholes was analyzed by EDX.

The number of pits in $500 \mathrm{~mm}$ of beads was visually counted, while the number of blowholes in $100 \mathrm{~mm}$ was counted in an X-ray test; and the results are compared.

\section{Experimental Results and Discussion}

\subsection{Cause of Gas Pocket Generation}

A typical example of the gas pocket (pit, blowhole) generation in the welding of galvanized steel sheets is shown in Fig. 2. The wall of such a blowhole as analyzed by EDX is also shown in Fig. 3. These results indicate the presence of $\mathrm{Zn}$ on the wall of the blowhole. The gas analysis reveals, as shown in Table 5, the little presence 


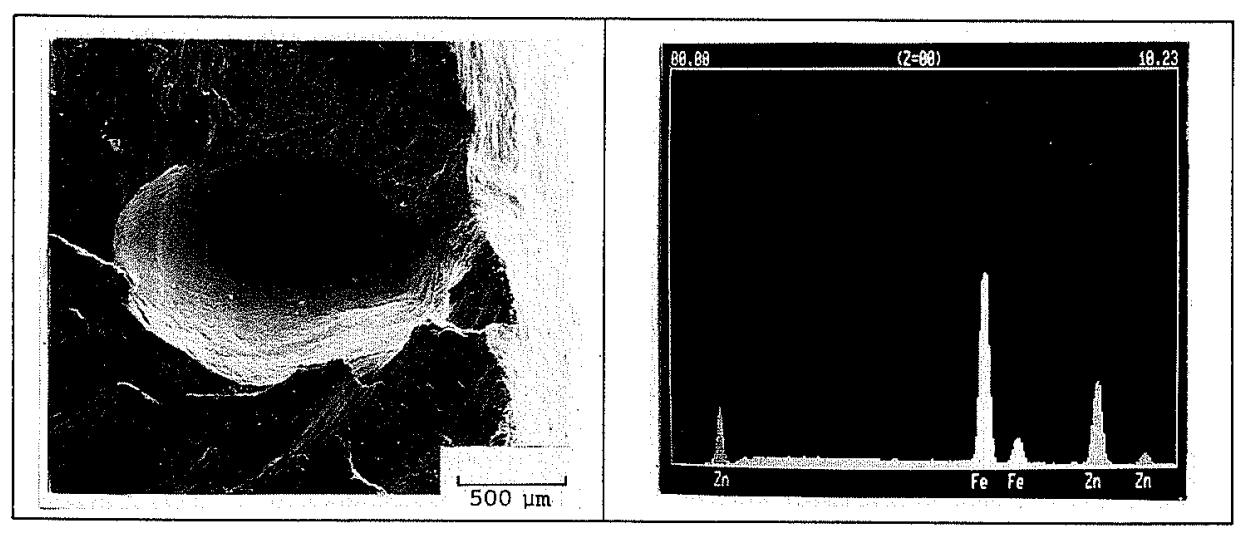

(a) SEM image

(b) EDX analysis

Fig. 3. Result of SEM and EDX analysis of wall of blowhole.

Table 5. Result of gas chromatography analysis of gas in blowhole. (vol\%)

\begin{tabular}{lccccccc}
\hline & $\mathrm{H}_{2}$ & $\mathrm{Ar}$ & $\mathrm{N}_{2}$ & $\mathrm{CH}_{4}$ & $\mathrm{CO}$ & $\mathrm{O}_{2}$ & $\begin{array}{c}\text { Total } \\
(\mu l)\end{array}$ \\
\hline $\begin{array}{l}\text { Weld metal } \\
\text { Blank }\end{array}$ & 84.1 & - & 6.8 & 9.1 & - & - & 0.44 \\
\hline
\end{tabular}

Solid wire $(1.2 \mathrm{~mm} \phi), 100 \% \mathrm{CO}_{2}(20 / / \mathrm{min}), 120 \mathrm{~A} \times 60 \mathrm{~cm} / \mathrm{min}$, Lap joint, Flat position, Thyristor controlled power source, Zinc coated amount $\left(90 / 90 \mathrm{~g} / \mathrm{m}^{2}\right)$.

\section{of $\mathrm{H}_{2}$ and $\mathrm{N}_{2}$.}

It seems from Fig. 3 and Table 5 that the major cause of the gas pocket generation is $\mathrm{Zn}$ in this experiment. Namely it is likely that $\mathrm{Zn}$ on the lapped surface is vaporized by the arc heat; and when the vaporized gas goes through the molten pool and then is released outside, the solidification of the molten pool confines the gas, thereby forming a blowhole.

Concerning the cause of the blowhole formation in the welding of galvanized steel sheets, one report attributes it to $\mathrm{H}_{2},{ }^{5)}$ while another does to $\mathrm{Zn} .{ }^{6-8)}$

\subsection{Relation between Gas Pocket Generation and Welding Conditions}

The influences on the gas pocket generation of various factors such as zinc coated amount, root gap (opening of steel sheets), joint type, welding current, arc voltage, welding speed, torch angle, tip to sheet distance, shielding gas composition, gas flow rate, base metal thickness and so on have been investigated. Those factors which are found more influential, i.e., zinc coated amount, root gap, joint type, welding current, shielding gas composition and welding position are discussed in detail.

\subsubsection{Influences of Zinc Coated Amount, Root Gap and Joint Type}

Some examples of experimental results about the influences of these factors on the gas pocket generation are shown in Figs. 4, 5 and 6. It is seen from Figs. 4 and 5 that at flat position with lap joint, the increase in zinc coated amount and the decrease in root gap increase the number of pits (the results are equivalent to those in literatures 7,8 and 9).

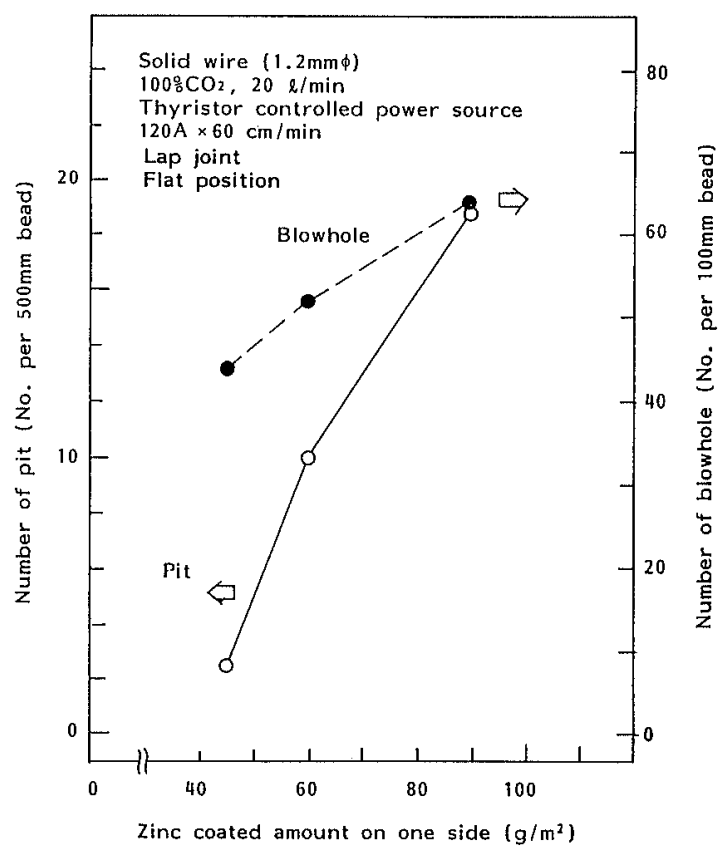

Fig. 4. Effect of zinc coated amount on gas pocket generation.

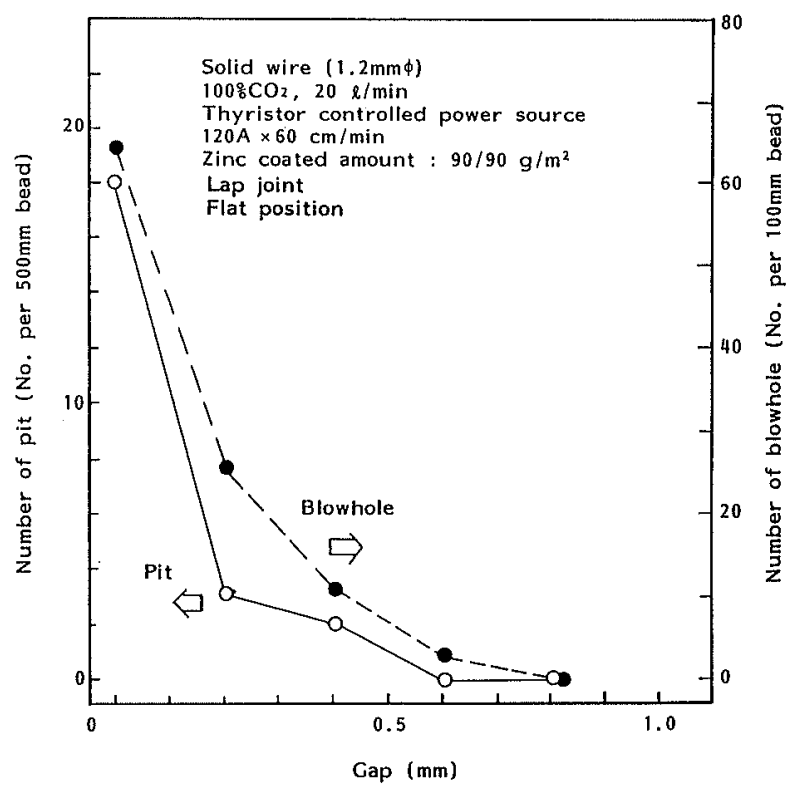

Fig. 5. Effect of root gap on gas pocket generation. 


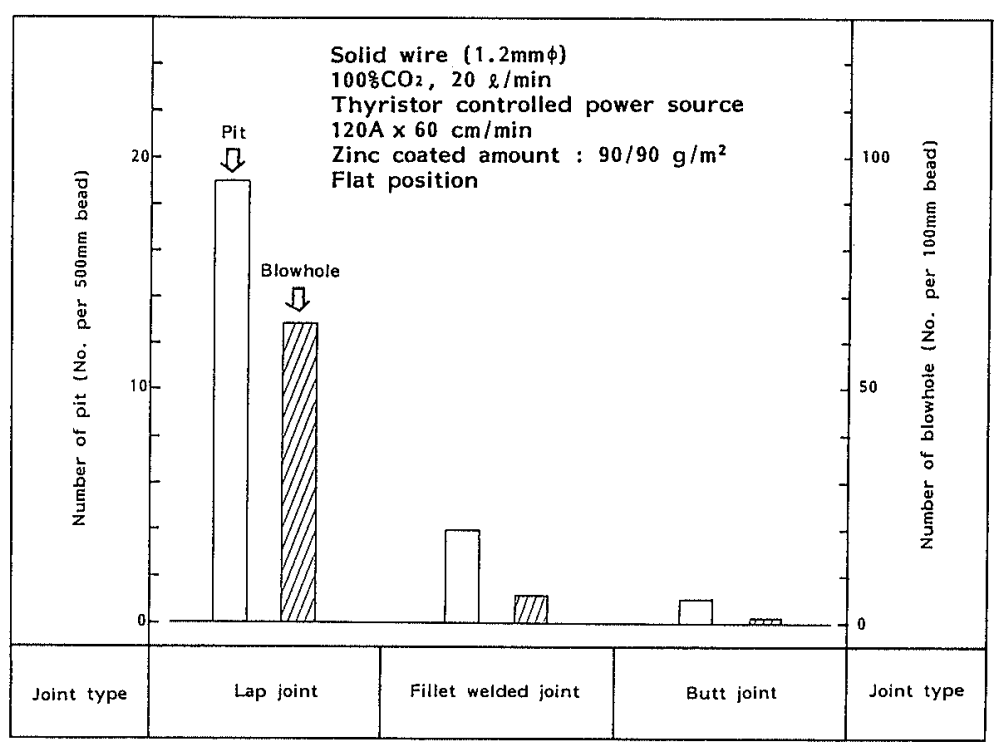

Fig. 6.

Comparison of gas pocket generation in various joint types.

Figure 6 indicates the difference in the number of pits depends on the joint types. The difference indicated may be accounted by the amount of zinc vapor and the ease of its release from the molten pool to the air, and the above-mentioned theory of the gas pocket generation mechanism seems to be well-founded.

\subsubsection{Influences of Welding Current and Welding Speed}

An example of experimental results about the influences of welding current and welding speed on the gas pocket generation is illustrated in Fig. 7. In this experiment, the deposition rate is kept at a constant state.

From this figure it is seen that as the welding current and the welding speed increase, the number of gas pockets increases. This phenomenon may be explained as follows: as indicated in Table 6, the penetration depth increases with the increase in the welding current and the welding speed, and in consequence the generation of zinc vapor, which is the source of gas pockets, grows. In these welding, the type of droplet transfer is short-circuiting one so that as the welding current grows, the arc and the droplet transfer come to be unstable. It induces the excessive agitation of the molten pool, which promotes the coming up of zinc vapor through the molten pool and its release to the air, and thus leads to this phenomenon.

\subsubsection{Influence of Shielding Gas Composition}

An example of experimental results showing the influence of shielding gas composition on gas pocket generation is given in Fig. 8.

As is evident from this figure, the increase in the $\mathrm{CO}_{2}$ content content of the shielding gas decreases the number of gas pockets. As for the penetration depth of joints, it is not distinctly affected by the shielding gas composition. Therefore its influence may be explained as follows; in $\mathrm{CO}_{2}$ arc welding unlike in $\mathrm{Ar}-\mathrm{CO}_{2}$ arc welding, shortcircuiting occurs more frequently and regularly. In consequence, the agitation of the molten pool is promoted, ${ }^{4)}$ which in turn facilitates the coming up of zinc vapor through the molten pool and its release to the air, and gives rise to the decrease of the gas pocket

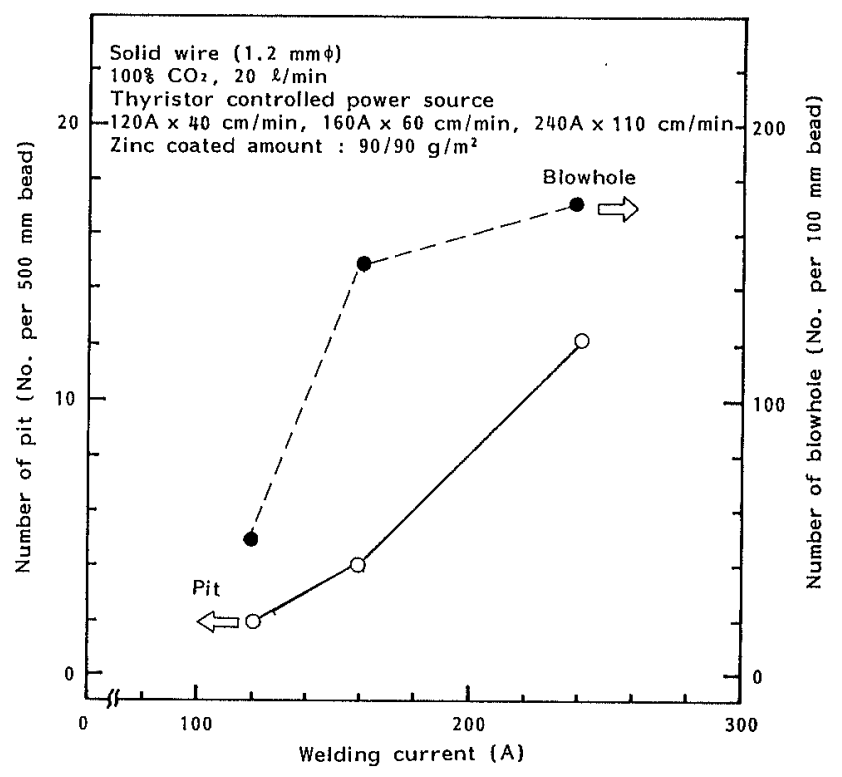

Fig. 7. Effects of welding current and speed on gas pocket generation.

generation.

\subsubsection{Influence of Welding Position}

Figure 9 illustrates the relation between welding positions and the number of the gas pocket.

The experiment was conducted with the welding current, the welding speed and the tip to plate distance kept at a constant state. It seems that more pockets are generated under vertical-down position than under the other positions. The reasons are speculated as follows; the coming up and release of zinc vapor gathers at the solidifying area of the molten pool and the throat thickness of the area is thinner under vertical-down position. And in addition to these facts, the molten pool is unstable induced by the irregularity of the droplet transfer.

The tendencies disclosed in Secs. 3.2.1, 3.2.2, 3.2.3, and 3.2.4 are the results of the present experiments. And the results on the influences of welding current and welding speed are equivalent to those in literature 10, and the influence of welding position is equivalent to 
that in literatures 7 and 8 .

It should be noted that the tendencies may turn out different from the above, when the zinc coated amount, the root gap, the penetration depth and the ease of coming

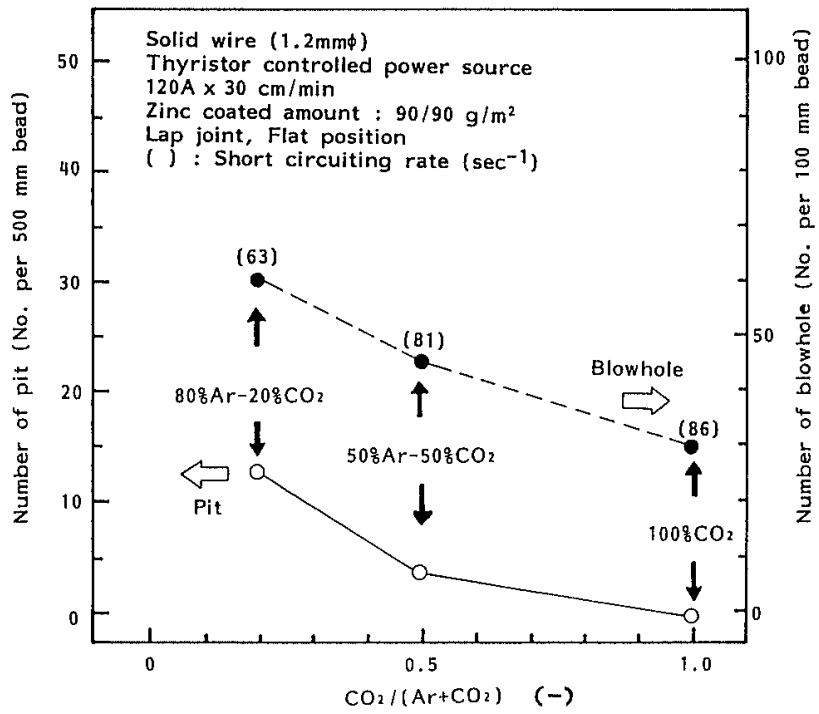

Fig. 8. Effect of shielding gas composition on gas pocket generation. up and release of the zinc vapor change complicatedly in a practical welding.

\subsection{Relation between Gas Pocket Generation and Wire Composition}

\subsubsection{Comparison of Various Wires}

Various wires are compared in terms of restraint to the gas pocket generation in Fig. 10. Among the wires investigated, the metal-cored wire ${ }^{11)}$ exhibits the most efficient result. It is confirmed that the performance of this wire is close to that of the covered electrode.

The excellent performance of the metal-cored wire is likely related to the following characteristics of this wire;

(1) Less slag is produced (same as the solid wire) and accordingly the zinc vapor is more easily released.

(2) Penetration is relatively shallow (compared with the solid wire) and accordingly less zinc is molten.

(3) Short-circuiting, that is the droplet transfer, is stable and in consequence, the convection and the agitation of molten pool controlling the coming up and release of the zinc vapor take place regularly.

Table 7 shows the penetration and the arc stability (the waveform of the current and the voltage, the frequency of the short-circuiting) in the welding of

Table 6. Effects of welding current and speed on penetration depth and short-circuiting rate.

\begin{tabular}{|c|c|c|c|}
\hline No. & 1 & 2 & 3 \\
\hline $\begin{array}{l}\text { Sectional } \\
\text { photo. and } \\
\text { penetration } \\
\text { depth }\end{array}$ & 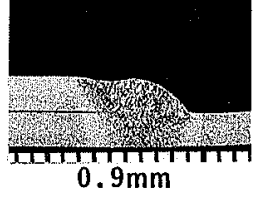 & 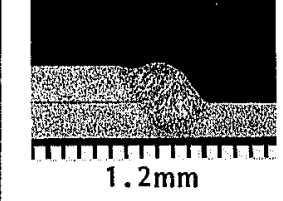 & 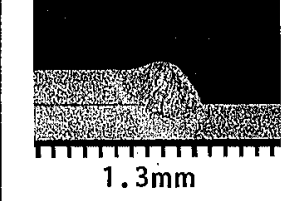 \\
\hline $\begin{array}{l}\text { Welding } \\
\text { condition } \\
\text { (Heat input) }\end{array}$ & $\begin{array}{c}120 \mathrm{~A} \times 40 \mathrm{~cm} / \mathrm{min} \\
(3420 \mathrm{~J} / \mathrm{cm})\end{array}$ & $\begin{array}{c}160 \mathrm{~A} \times 60 \mathrm{~cm} / \mathrm{min} \\
(3120 \mathrm{~J} / \mathrm{cm})\end{array}$ & $\begin{array}{c}240 \mathrm{~A} \times 110 \mathrm{~cm} / \mathrm{min} \\
(3080 \mathrm{~J} / \mathrm{cm})\end{array}$ \\
\hline $\begin{array}{l}\text { Short } \\
\text { circuiting } \\
\text { rate }\end{array}$ & $88 \mathrm{sec}^{-1}$ & $71 \mathrm{sec}^{-1}$ & $46 \sec ^{-1}$ \\
\hline
\end{tabular}

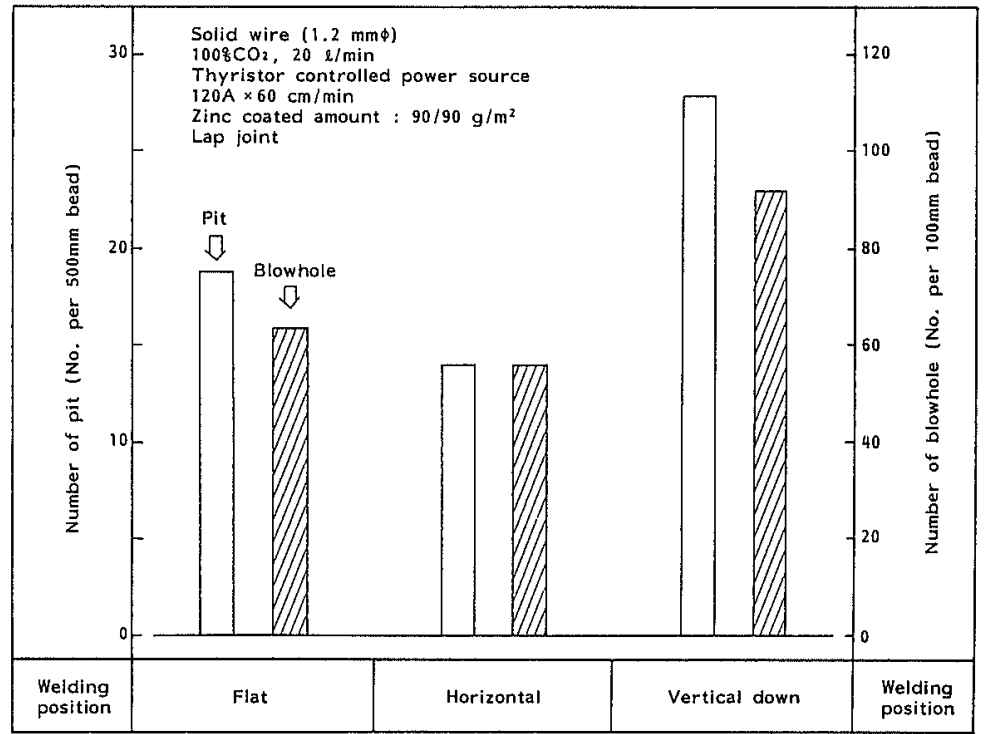

Fig. 9.

Comparison of gas pocket generation in various welding positions. 
galvanized steel sheets using the metal-cored wire as compared with the case using the solid wire.

From this table, the effects of (2) and (3) mentioned above are verified.

\subsubsection{Influence of Wire Composition}

Based on the results described in Sec. 3.3.1, the influence of wire compositions on the gas pocket generation was investigated using a metal-cored wire.

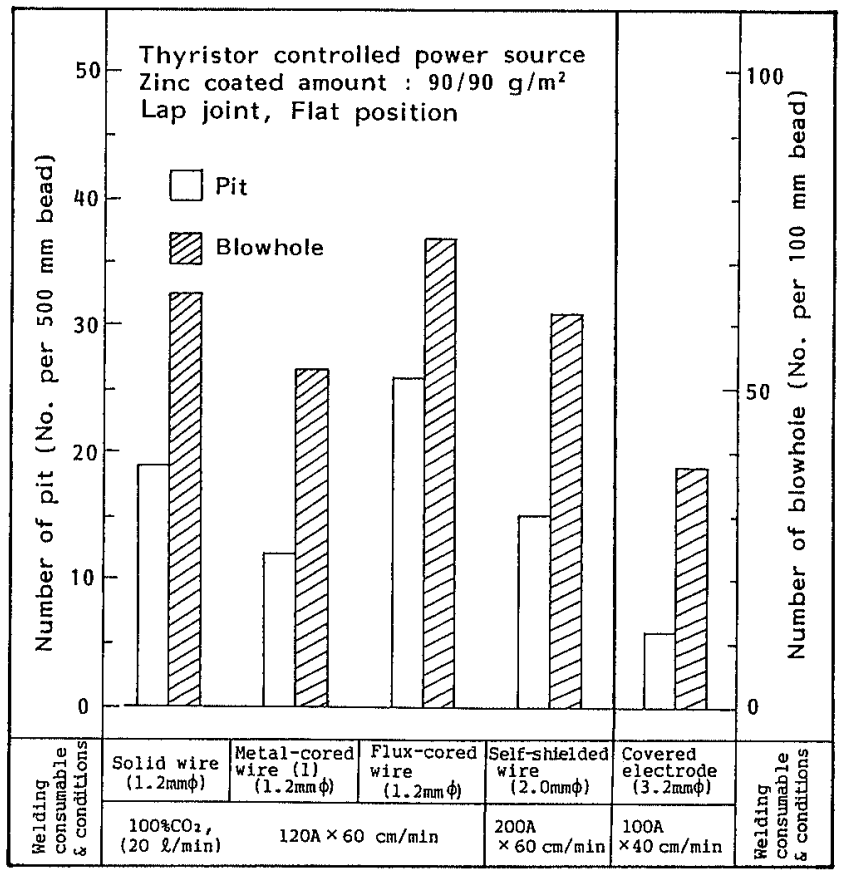

Fig. 10. Comparison of gas pocket generation in various welding consumables.
The results of the investigation are summarized in Figs. 11, 12 and 13. From these figures, it follows that the increase in the wire contents of $\mathrm{C}, \mathrm{P}$ and $\mathrm{Ti}$ will be effective to suppress the gas pocket generation. In the present experiment the effect of $\mathrm{Mn}$ and $\mathrm{Si}$ is not prominent, but the increase in these elements does decrease the number of gas pockets to a certain extent.

The effect of $\mathrm{C}$ to decrease the number of gas pockets may be ascribed to the regular and promoted agitation of the molten pool, which is brought by the increased frequency of short-circuiting ${ }^{12)}$ and the improved stability of the droplet transfer produced by the increase in $\mathrm{C}$ content. And it makes the coming up and release of zinc vapor easy.

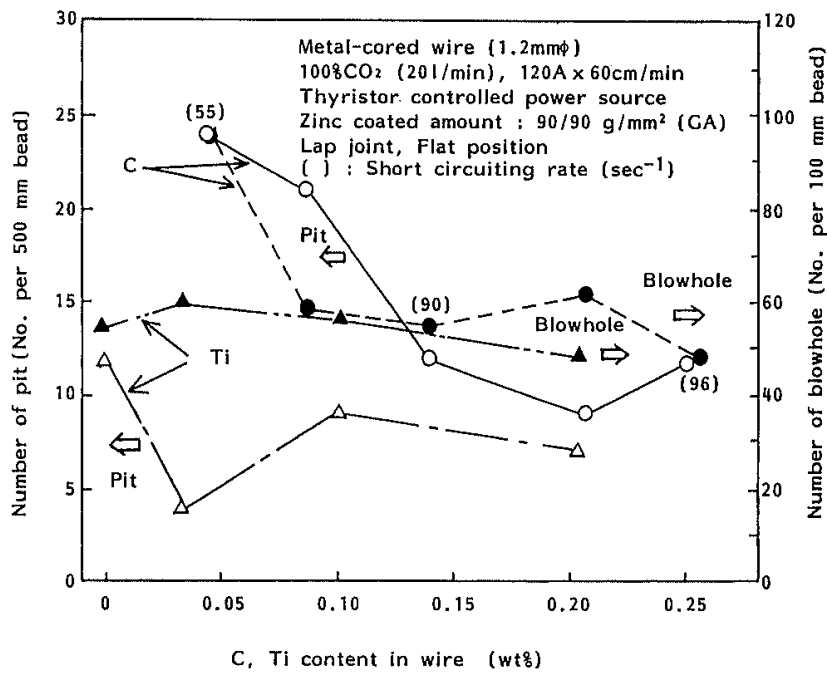

Fig. 11. Effects of $\mathrm{C}$ and $\mathrm{Ti}$ content in wire on gas pocket generation.

Table 7. Differences in penetration depth and arc stability between solid wire and metal-cored wire.

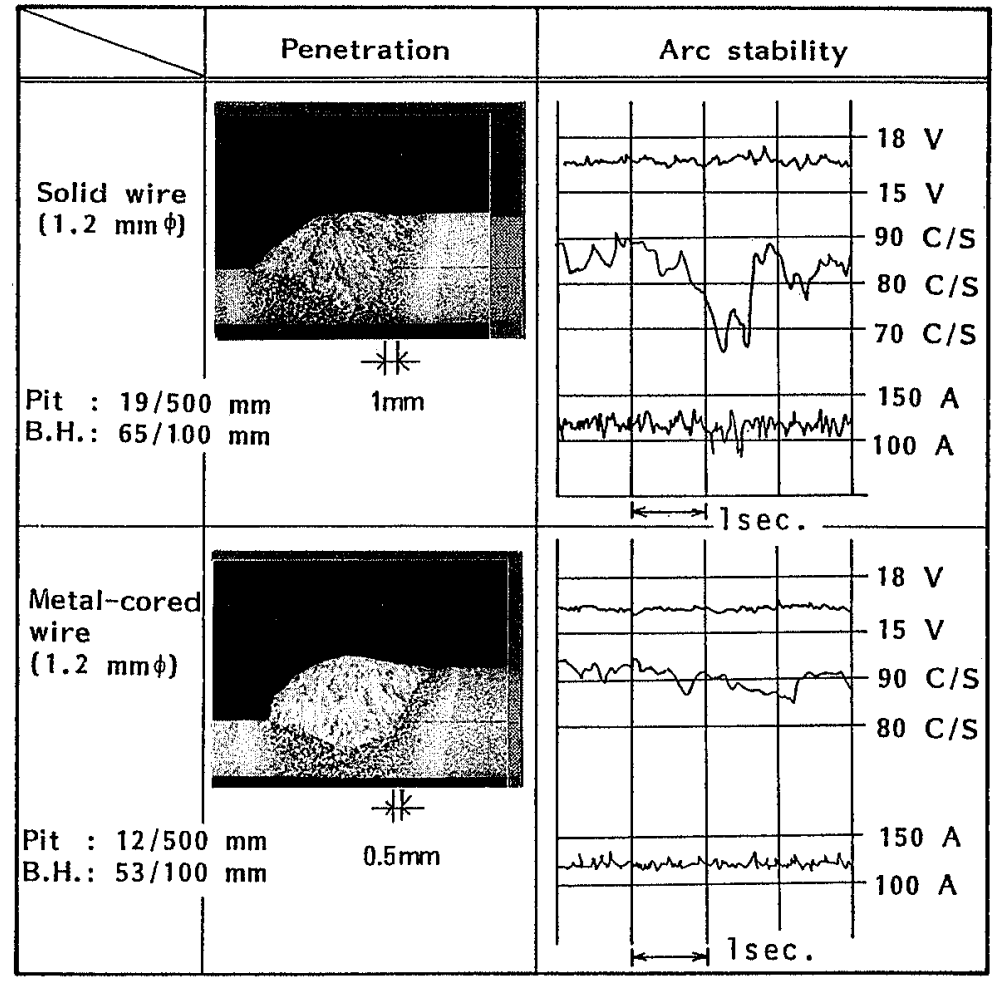

$100 \frac{\circ}{6} \mathrm{CO}_{2}(20 \mathrm{l} / \mathrm{min})$. Thyristor controlled power source $120 \mathrm{~A} \times 60 \mathrm{~cm} / \mathrm{min}$, Zinc coated amount : $90 / 90 \mathrm{~g} / \mathrm{m}^{2}$ 


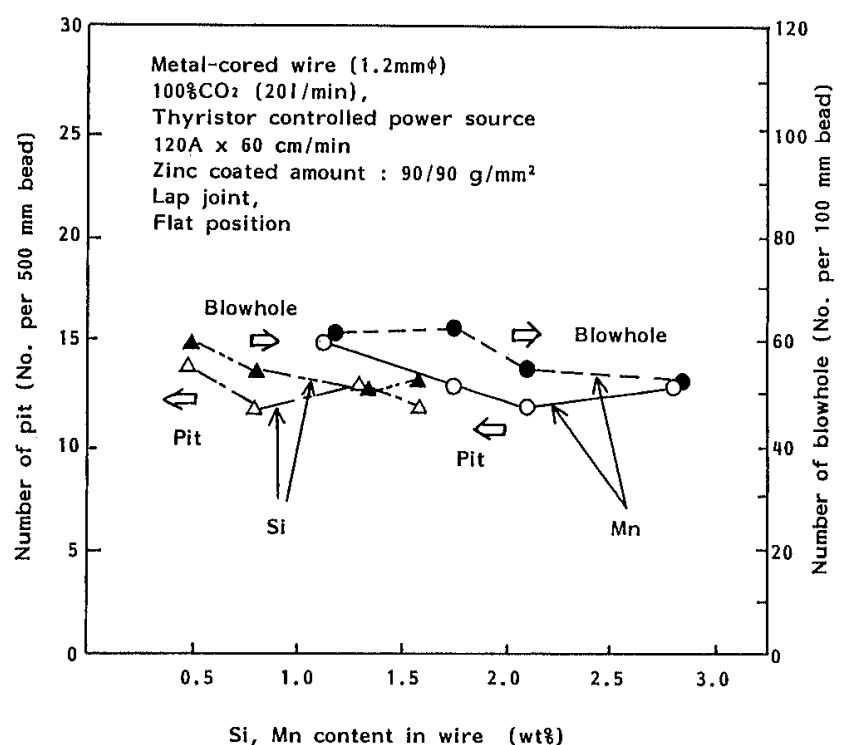

Fig. 12. Effects of $\mathrm{Si}$ and $\mathrm{Mn}$ content in wire on gas pocket generation.

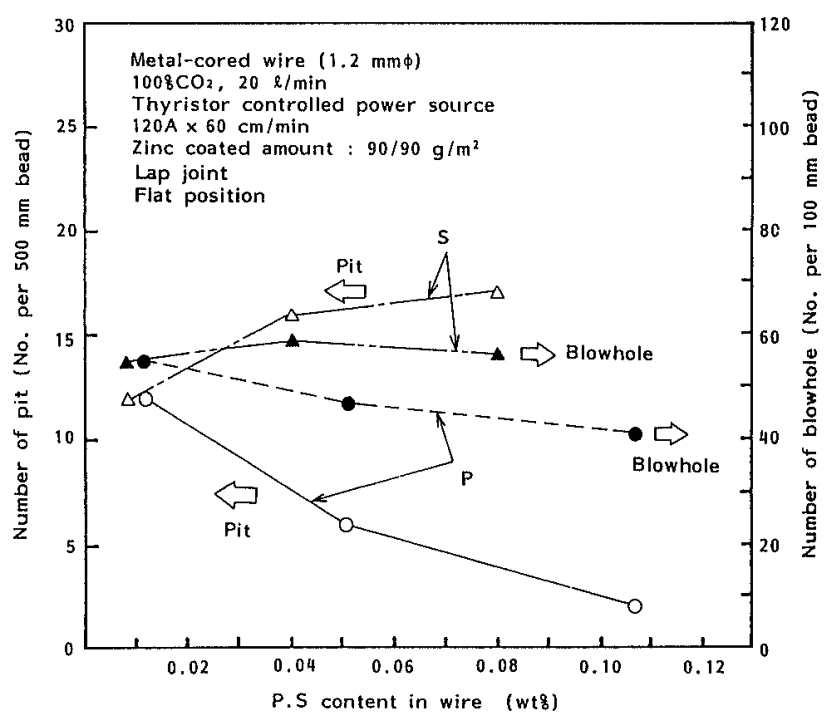

Fig. 13. Effects of $\mathrm{P}$ and $\mathrm{S}$ content in wire on gas pocket generation.

As to the effect of $P$, no definite is known. But it is likely that $P$ combines with $\mathrm{Zn}$ to produce $\mathrm{Zn}_{3} \mathrm{P}_{2}$, $\mathrm{ZnP}_{2}{ }^{13)}$ and these compounds contribute to the suppression of zinc vaporization.

As to $\mathrm{Ti}$, this element probably increase the viscosity or surface tension of the molten metal ${ }^{14)}$ by itself and through the oxidation of the molten metal. And thereby it suppress the generation and growth of gas pockets. A certain effect of $\mathrm{Mn}$ and $\mathrm{Si}$ can also be attributed to the increase in the viscosity or surface tension of the molten metal, which is mainly brought by the decrease in the oxygen content of the molten metal. ${ }^{15}$ )

Based on these experimental results, the metal-cored wire (featuring the high resistance to the gas pocket generation and the low spatter generation) intended for the welding of galvanized steel sheets has been successfully developed. ${ }^{16)}$ Table 8 gives the performance of the new wire as tested referring to JIS.

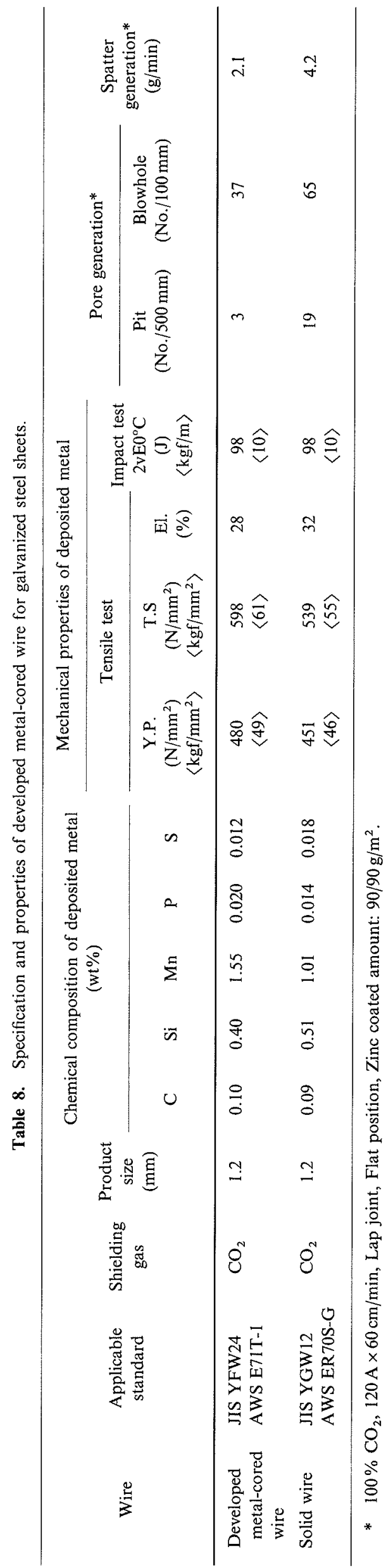




\subsection{Influence of Welding Power Source}

The influence of welding power source on the gas pocket generation has been studied using the metal-cored wire for the welding of galvanized steel sheets as mentioned in Sec. 3.3.2. The results being summarized in Fig. 14 indicate that under $\mathrm{CO}_{2}$ gas shield, the inverter-controlled power source slightly excels over the other types in the restraint of the gas pocket generation. One of the reasons is supposed that the power source comparatively stabilizes the agitation of the molten pool through the stability of the arc and the droplet transfer, which facilitates the coming up and release of the zinc

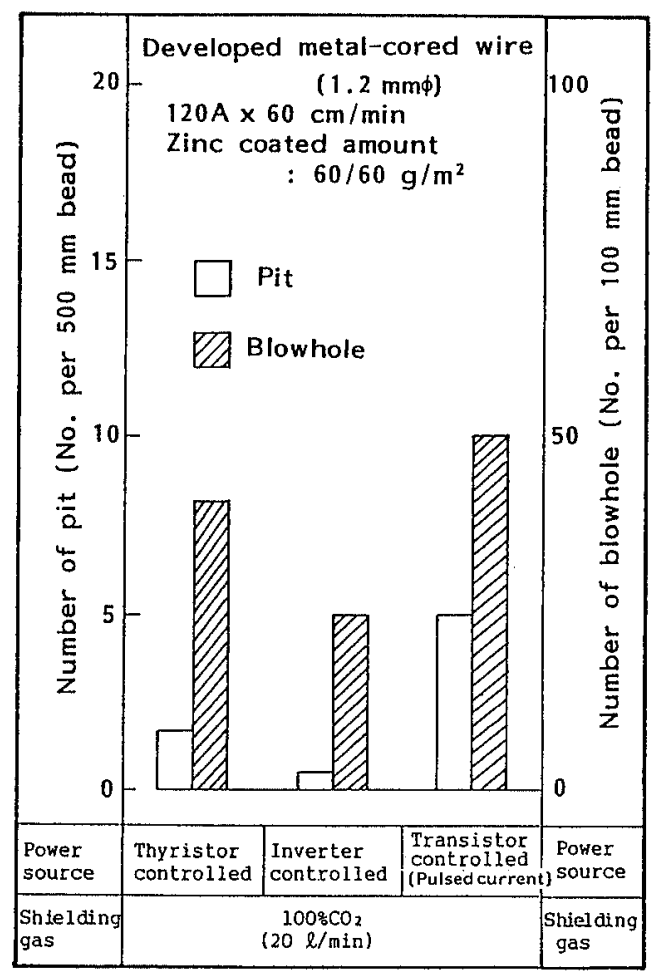

Fig. 14. Comparison of gas pocket generation in various power sources.

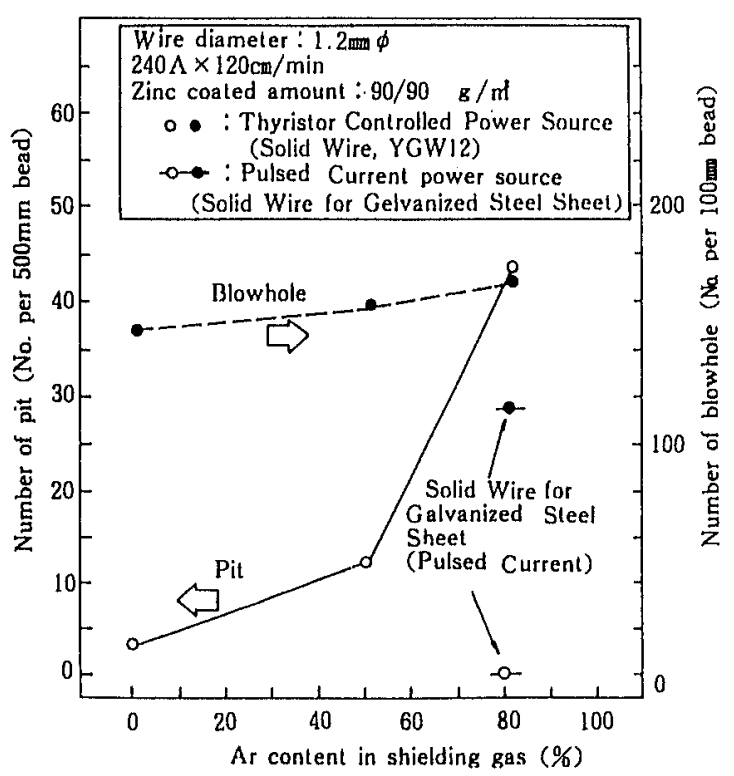

Fig. 15. Effect of combinations of solid wire with power source in various shielding gas compositions on gas pocket generation. vapor.

As to the solid wire, it has been verified that as indicated in Fig. 15, the number of gas pocket can be reduced under the appropriate combination of the wire composition with the pulse condition of welding current in a gas shield of $80 \% \mathrm{Ar}-20 \% \mathrm{CO}_{2} \cdot{ }^{17)}$ Figure 16 illustrates the waveforms of the welding current and the arc voltage under the optimum conditions of pulsed MAG welding in comparison with those of MAG welding using the thyristor controlled power source. The waveforms in pulsed MAG welding show how the droplet transfers periodically with excellent stability. The frequency of the droplet transfer is around 6 times as many as that of the case using thyristor controlled power source. Thus it can be presumed that the periodically agitated molten pool promotes the coming up and release of the zinc vapor, and in consequence the generation of gas pocket is suppressed.

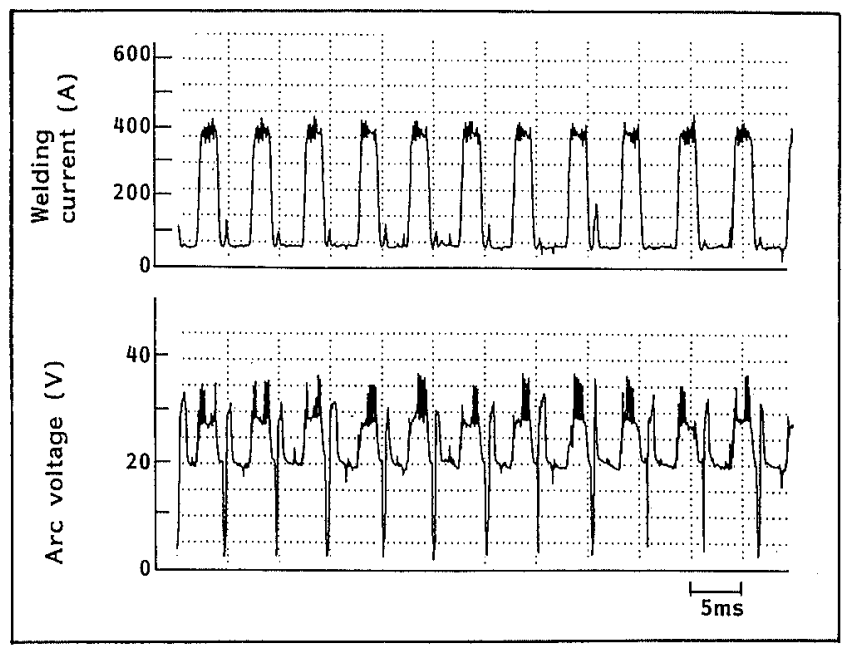

(a) Pulsed current power source $\left(\begin{array}{l}I_{p}=460 A, T_{p}=1.8 \mathrm{~ms} \\ \left.\text { Short circuiting rate : } 180 \mathrm{sec}^{-1}\right)\end{array}\right)$

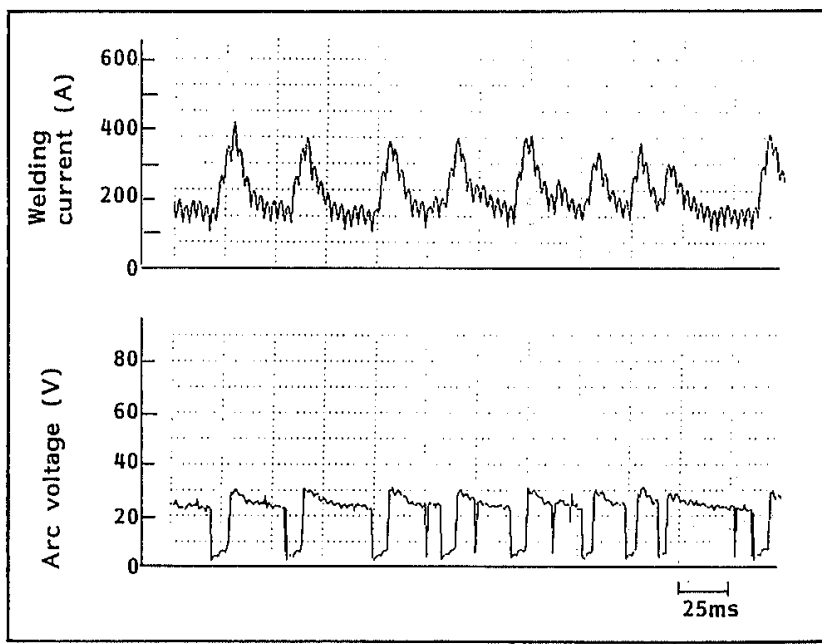

(b) Thyristor controlled power source (Short circuiting rate : $32 \mathrm{sec}^{-1}$ )

Fig. 16. Comparison of waveforms of welding current and arc voltage between pulsed MAG welding and MAG welding.

(Solid wire $(1.2 \mathrm{~mm} \phi), \mathrm{Ar}-20 \% \mathrm{CO}_{2} \quad(20 \mathrm{l} / \mathrm{min})$, $240 \mathrm{~A}-120 \mathrm{~cm} / \mathrm{min}$, Zinc coated amount: $90 / 90 \mathrm{~g} / \mathrm{m}^{2}$ ) 


\section{Concluding Remark}

In this paper the influence of various factors on the generation of gas pocket in the welding of galvanized steel sheets have been studied. It is concluded that the proper selection of welding conditions (low current, low speed), the introduction of the metal-cored wire under $\mathrm{CO}_{2}$ gas shield, and the adoption of a pulsed current power source under the appropriate combination of a solid wire with $\mathrm{Ar}-\mathrm{CO}_{2}$ gas shield, will be effective.

\section{REFERENCES}

1) S. Nomura: Kobe Steel Eng. Rep., 39 (1989), No. 1, 3.

2) I. Masumoto, K. Matsuda and M. Hasegawa: J. Jpn. Weld. Soc., 42 (1973), No. 12, 57

3) M. Takenouchi and T. Shimizu: J. Jpn. Weld. Soc., 60 (1991), No. 6,38 .

4) Study of Welding, No. 25, ed. by Jpn. Weld. Eng. Soc., T. Godai, Tokyo, (1985), 45.

5) Y. Mukai, A. Nishimura, A. Nakajima and K. Oku: Q.J. Jpn. Weld. Soc., 7 (1989), 70.

6) K. Yasuda, S. Nakano, T. Komatsu and T. Nakajima: Preprints of the National Meeting of Jpn. Weld. Soc., Vol. 43, (1988), 164.
7) T. Suzuki, H. Koyama and Y. Kanbe: No. 102 Technical Commission on Physics of Welding Arc, No. 91-763, (1991).

8) H. Matsui, H. Suzuki and M. Yamada: No. 105 Technical Commission on Physics of Welding Arc, No. 92-795, (1992).

9) H. Yamamoto, S. Harada and T. Yasuda: Weld. Tech., 37 (1989), No. 2, 67 .

10) Y.Sugitani, Y. Sato and N. Goto: No 136 Technical Commission on Welding Processes, SW-1301-92, (1992).

11) Y. Sakai, I. Aida, T. Suga, T. Hashimoto and T. Nakano: Preprints of the National Meeting of Jpn. Weld. Sec., Vol. 41, (1987), 254.

12) T. Arai, M. Rokujo, T. Yamada and T. Suga: Q.J. Jpn. Weld. Soc., 1 (1983), No. 2, 177.

13) T. B. Massalski, H. Okamoto, P. R. Subramanian and L. Kacprzak: Binary Phase Diagrams, 2nd ed., 3, ASM International, Ohio, (1990), 2995.

14) Handbook of Physical Properties for Molten Iron and Slags, ed. by the Iron and Steel Inst. of Jpn., Ibaraki Printing Co., Osaka, (1972), 46, 50, 124, 127.

15) Handbook of Physical Properties for Molten Iron and Slags, ed. by the Iron and Steel Inst. of Jpn., Ibaraki Printing Co., Osaka, (1972), 44, 46, 49, 124, 126, 127, 129.

16) T. Suga: Kobe Steel Eng. Rep., 38 (1988), No. 4, 77

17) Y. Sakai and T. Suga: JoyTech, 7 (1991), No. 12, 18 